\title{
Introduction: outlining the field of cultural rights and its importance
}

\section{Lucky Belder and Helle Porsdam}

\section{THE MANDATE AND THIS VOLUME}

The Human Rights Council established the mandate of the United Nations Special Rapporteur in the Field of Cultural Rights in 2009 with Resolution 10/23. It was Cuba that, as a member of the Council, introduced this Resolution and conducted the procedural and diplomatic process leading up to its adoption by the Council, and it is Cuba that is in charge of the yearly resolutions of the Council as well as of the renewal of the mandate every three years. ${ }^{1}$

Pakistani sociologist and feminist human rights activist Farida Shaheed was appointed as the first Independent Expert and continued as Special Rapporteur in the period between 2009 and 2015. During her tenure she published ten thematic reports on the following topics: preliminary views on the conceptual framework for the mandate (2010), the right to access and enjoy cultural heritage (2011), the right to enjoy the benefits of scientific progress and its application (2012), cultural rights of women on an equal basis with men (2012), the right to the freedom of artistic expression and creativity (2013), the writing and teaching of history (2013), memorialization processes (2014), the impact of advertising and marketing practices on the enjoyment of cultural rights (2014), and the impact of copyright and patent policies on the enjoyment of the right to science and culture (two separate reports published in 2015). ${ }^{2}$

Shaheed's list of thematic reports may, as Mylène Bidault (the Office of the High Commissioner for Human Rights staff member overseeing the drafting of Shaheed's reports) puts it, 'appear eclectic'. But the

\footnotetext{
1 See Bidault (2016).

2 All reports are available on the website of the Office of the High Commissioner for Human Rights at http://www.ohchr.org/EN/Issues/Cultural Rights/Pages/AnnualReports.aspx.
} 
themes are not only 'all linked and articulated together in various ways and degrees'; they also by and large follow the structure of Article 15 of the International Covenant on Economic, Social and Cultural Rights (ICESCR) which, together with Article 27 of the Universal Declaration on Human Rights, forms a major legal basis for cultural rights. ${ }^{3}$ These provisions protect the right of every person to: (i) participate in cultural life; (ii) to enjoy the arts and the benefits of scientific progress and its applications; and (iii) to benefit from the protection of the moral and material interests resulting from any scientific, literary or artistic production of which he or she is the author.

Together, Shaheed's ten thematic reports provide a new standard on cultural rights. This volume highlights these reports and discusses how cultural rights are now part of a global discourse for supporting inclusive social and political development, and for fostering intercultural dialogue for the mutual understanding of cultures. We see the volume as a contribution to current debates concerning cultural rights and have invited the contributors to reflect upon the main conclusions concerning the meaning and the position of cultural rights in Shaheed's reports, as well as on what the implications of these conclusions may be for international relations, the international legal order, and for crosscultural understanding.

At a scholarly level, new and important works on culture, cultural heritage, and human rights are helping to increase the interest in this particular corner of human rights research. The last few years have seen the publication of, among others, Helaine Silverman and D. Fairchild Ruggles, Cultural Heritage and Human Rights (Berlin: Springer, 2007); Yvonne Donders and Vladimir Volodin (eds), Human Rights in Education, Science and Culture (UNESCO and Ashgate, 2007); Francesco Francioni and Martin Scheinin, Cultural Human Rights (Leiden, NLD: Martinus Nijhoff, 2008); James A.R. Nafziger, Robert Kirkwood Paterson, and Alison Dundes Renteln (eds.), Cultural Law: International, Comparative, and Indigenous (Cambridge: Cambridge University Press, 2010); Olivier de Schutter (ed.), Economic, Social and Cultural Rights as Human Rights (Cheltenham, UK, and Northampton MA: Edward Elgar, 2013); Federico Lenzerini, The Culturalization of Human Rights Law; Ana F. Vrdoljak, The Cultural Dimension of Human Rights (both Oxford University Press, 2014); Aurora Plomer, Patents, Human Rights and Access to Science (Cheltenham, UK, and Northampton MA: Edward

3 Bidault (2016), 22. 
Elgar, 2015); and Christophe Geiger (ed.). Intellectual Property and Access to Science and Culture: Convergence or Conflict? (CEIPI-ICTSD, 2016).

\section{TWO KEY ISSUES IN THE FIRST REPORT}

In her first report, Shaheed points to key provisions from the International Covenant on Civil and Political Rights (ICCPR) as well as to Article 13 ICESCR (the right to education) and various provisions and instruments relating to indigenous people and minorities as being relevant for her mandate. The first report identifies and addresses two key issues on which there has been much disagreement over the years: the relationship between cultural diversity and cultural relativism, and the relationship between group rights and individual rights.

\section{(a) The Relationship Between Cultural Diversity and Cultural Relativism}

Many originally thought and argued that cultural rights would automatically lead to the promotion of cultural relativism, and that all human rights would suffer as a result. As William Logan put it much later, 'cultural rights are clearly related to cultural diversity and cultural diversity is an obvious challenge to the very idea of universal human rights' ${ }^{4}$ In her first report, Shaheed chose to settle this issue by affirming that cultural rights, like all human rights, are universal. In 2009, General Comment 21 on the right to the enjoyment of cultural life had stated that the protection of cultural rights is incomplete without the ethical imperative of the protection of cultural diversity. ${ }^{5}$ Respect, protection and promotion of cultural diversity being essential for ensuring the full respect of cultural rights means neither, however, that cultural diversity can be invoked to infringe upon or limit the scope of human rights guaranteed by

\footnotetext{
4 William Logan (2012) in reference to the Academy of European Law 2005 'cultural rights are clearly related to cultural diversity and cultural diversity is an obvious challenge to the very idea of universal human rights', p. 239.

5 Recognition of the importance of 'cultural diversity' is global. This is reflected in e.g., the Charter of the European Union; the Culture Conventions of the Council of Europe, the 2006 Declaration on ASEAN Unity in Cultural Diversity; and The 2006 Charter of the African Renaissance of the African Union.
} 
international legal instruments, nor that all cultural practices are automatically condoned by these instruments, Shaheed argues:

The principle of universality of human rights, one of the core principles of international human rights law, on the one hand, and cultural rights and cultural diversity on the other, are sometimes considered as opposed. This view stems partly from a misplaced tendency to equate cultural diversity with cultural relativism, which has the effect of raising fears and misunderstanding regarding the recognition and implementation of cultural rights ... Therefore, not all cultural practices can be considered as protected in international human rights law. ${ }^{6}$

Complex as the relationship between the unconditional protection of cultural diversity and the protection of cultural rights may seem, they are mutually supportive. ${ }^{7}$ Respect for human rights entails the creation of an enabling environment for cultural diversity. Such an environment will in turn promote cultural rights, but it will also allow people to be sensitive to the dangers involved when the interests of some are trespassing on the interests of others. This should ideally make it impossible for people anywhere to refer to tradition, culture and/or religion as legitimizing infringements of human rights, especially women's rights. ${ }^{8}$

In her reflections on the significance and challenges of the cultural rights mandate (Chapter 1 in this volume), Shaheed again addresses the relationship between cultural rights and cultural diversity. Always dynamic and forever changing, culture inevitably relates to power and to disagreement and negotiation concerning meanings and worldviews, she writes. ${ }^{9}$ All societies have a dominant culture whose members seek to enforce their own cultural views, and these views are under constant challenge by members of minority groups who wish to have their respective views and needs to belong recognized: 'Power differentials impact the ability of individuals and groups to effectively contribute to the identification, development and interpretation of what should be considered as a common "culture" both in terms of shared cultural heritage from the past and in terms of contemporary cultural life.' 10

It is important, furthermore, Shaheed argues, to separate both culture per se and the preservation of culture or cultural heritage from cultural

\footnotetext{
6 A/HRC/14/36, esp. paras 32-34. See also Bidault (2016).

7 Ibid., para. 24.

8 Gender is one of the issues that the mandate asks the Special Rapporteur to focus on.

9 Farida Shaheed, Ch. 1, this volume.

10 Ibid.
} 
rights. Safeguarding cultural heritage is the responsibility of UNESCO. The cultural rights mandate concerns human creativity and the possibility for everyone to participate in and contribute to cultural life in an active way: 'The mandate is about ensuring that the necessary conditions exist for everyone to access, participate in and contribute to cultural life on a basis of equality and without discrimination; to question existing traditions and create new ones.' ${ }^{11}$ It is when the two - culture and cultural rights - are conflated that the end result may be cultural relativism.

\section{(b) The Relationship Between Individual Rights Versus Group Rights}

Shaheed likewise confronts head-on a second issue that has often been raised in relation to cultural rights: the relationship between the individual and the collective dimensions of these rights. Group rights have been recognized in countless human rights instruments, she notes. They do exist in practice in international human rights law today, especially in the UN Declaration on the Rights of Indigenous Peoples, just as various general comments by the Committee on Economic, Social and Cultural Rights have emphasized that cultural rights may be enjoyed alone, or in association with others or as a community. But this does not lead to:

the denial of individual cultural rights: individuals always enjoy their rights, inter alia, to participate or not to participate in one or several communities; to freely develop their multiple identities; to access their cultural heritage as well as that of others; and to contribute to the creation of culture, including through the contestation of dominant norms and values within the communities they choose to belong to as well as those of other communities. ${ }^{12}$

To approach access to cultural heritage as one of the key elements of the realization of cultural rights by focusing on the rights of the individual stakeholder in cultural heritage, as Shaheed does in her first report, solves the dilemma of individual versus group rights. The uniqueness of every human being, the bearer of multiple and complex identities, means that the right for everyone to take part in cultural life is considered as the right to take part in communities of shared culture and engage freely in cultural affiliations. ${ }^{13}$ Cultural practice is always collective, and "while an individual's identity showcases uniqueness, the collective identities

11 Ibid.

12 A/HRC/14/36, para. 10.

13 Ibid., para. 23. 
emphasise similarity,' as Shaheed beautifully puts it in her reflections on her mandate. ${ }^{14}$ The relationship between individual and collective rights is one that does need to be further explored, though, she correctly states in several of her reports. It will no doubt be taken up by her successor as Special Rapporteur, Karima Bennoune.

\section{TWO THEMES/ISSUES THAT UNDERLIE AND BIND TOGETHER ALL TEN REPORTS}

All Shaheed's reports display her trust in the rich possibilities for the field of cultural rights. This is particularly the case with regard to two issues, which may be said to bind her reports together, and which she repeatedly cross-references: cultural rights as empowering rights and the link between culture and science.

\section{(a) Cultural Rights as Empowering Rights and Discourse}

Cultural rights are potentially empowering once we realize, Shaheed writes, that they 'include freedoms and entitlements ... [for] all persons, without discrimination based on their particular identity(ies), and in a way that enhances the enjoyment of all human rights'. ${ }^{15}$ The message that cultural rights are for all persons - and not just for certain groups or minorities - is an important one to send at a time where majorities in various elections in Europe (Brexit) and the United States (the presidential election of 2016) seem to have been motivated, in part, by a feeling that (human) rights are not for them, but only for minority groups, and that their problems are of no concern to the international (human rights) community. The conception of cultural and other human rights as universal and not relative (though sometimes still context-dependent), as rights to be relied on in practice and not just in theory, is once again a timely and important one to develop and refine.

Delivering the opening address to the World Conference on Human Rights in Vienna in 1993, then Secretary-General of the United Nations, Boutros Boutros-Ghali, offered an interesting reflection on the complexity of human rights. At one and the same time both absolute and historically defined human rights, he said, have 'a dual nature':

\footnotetext{
14 Shaheed, Ch. 1.

15 A/HRC/14/36, para. 20.
} 
Human rights should be viewed not only as the absolute yardstick which they are, but also as a synthesis resulting from a long historical process. As an absolute yardstick, human rights constitute the common language of humanity. Adopting this language allows all peoples to understand others and to be the authors of their own history. Human rights, by definition, are the ultimate norm of all politics.

As an historical synthesis, human rights are in their essence, in constant movement. By that I mean that human rights have a dual nature. They should express absolute, timeless injunctions, yet simultaneously reflect a moment in the development of history. Human rights are both absolute and historically defined. ${ }^{16}$

Human rights - and here most people would agree - are by no means perfect. But precisely because they are both absolute/timeless and historically dependent, they constitute one of the few, if not indeed the only, (semi)-universal ethical discourse we have today. At a time of increasing globalization, where respect for cultural diversity takes center stage as a global concern, and where migration and advances in technology have increased the level of cultural exchange and intermingling, but have also fostered cultural clashes and incompatibilities that were previously masked by distance, we need a common forum or arena in which we can explain, negotiate, and come to new understandings. Culture permeates all human activities, including legal systems, in all communities. It is therefore important for us to work with law not only as a technical practice for ensuring social control, but also as a cultural vocabulary that recognizes people's aspirations for rights and justice, thereby enabling a common discussion among diverse communities who have no other common vocabularies.

Cultural rights have everything to do with cultural identity. The cultural heritage of a community is a way of expressing its identity, for example. This gives it a particular importance, both inside the community and with respect to its relations with the outside. Cultural heritage not only addresses the question of how a community is comprised and according to what values, it also functions as a way of telling those outside the community about the community and why it might deserve to be valued. ${ }^{17}$

In this relation, it bears repeating that human rights are the work of many actors and the product of global interactions. It was Cuba, as we saw, that was the prime mover behind Resolution 10/2. And new research has

16 B Boutros-Ghali, A/CONF.157/22: Address by the Secretary General of the United Nations at the Opening of the World Conference on Human Rights (1993), 3.

17 See Macmillan, 2017. 
shown that there is a vital connection between the decolonization process and human rights, that the duality of race and religion has been a driving force in the breakthrough for international human rights law, and that Jamaica and Liberia have been influential normative powers in twentieth century politics concerning human rights - all of which challenges us to rethink how Western the notion of human rights really is. ${ }^{18}$

Ahmed An-Na'Im, one of the first scholars to take the issue of cultural rights seriously, once maintained that 'the lack or insufficiency of cultural legitimacy of human rights standards is one of the main underlying causes of violations of those standards'. ${ }^{19}$ Cross-cultural legitimacy is important; people around the world are more likely to observe normative propositions if they believe them to be in accordance with and sanctioned by their own cultural traditions. This is no doubt the reason why, on the occasion of the 60th anniversary of the Universal Declaration of Human Rights (UHDR), the UN declared Culture to be one of six cross-cutting themes of the UN Agenda, the others being Dignity and Justice, Development, Environment, Gender, and Participation.

The 2008 choice of Culture as a cross-cutting theme was explained as follows:

... The concept of Human Rights is bound closely to the belief that culture is precious and central to our identity. The way we are born, live and die is affected by the culture to which we belong, so to take away our cultural heritage is to deny us our identity. At the same time, we can all benefit from our experience of other cultures and we have something to offer them in return. ${ }^{20}$

In the last few decades, cultural rights have become increasingly relevant in the context of globalization (post-colonialism, post 9/11, shifts in global power structures, cultural diversity) and the protection of intellectual property rights. Furthermore, cultural rights are seen as key to the realization of the Millennium Development Goals. ${ }^{21}$

\footnotetext{
18 See Jensen, 2016. See also Lenzerini, 2014.

19 An-Na'im, 1992, 19.

20 See http://www.ohchr.org/EN/UDHR/Pages/CrossCuttingThemes.aspx.

21 See Background Paper, 7 March 2014 for a meeting held at United Nations Headquarters in New York on Monday, 5 May 2014, in cooperation with UNESCO. The Background Paper and the accompanying letter are available at http://www.un.org/en/ga/president/68/pdf/letters/03072014TD\%20Culture\%20and $\% 20$ Sustainable\%20Development.pdf (last accessed on July 25, 2014).

See also the UNCTAD creative economy reports published every two years on global creative industries UNCTAD/PRESS/PR/2013/16, released 15 May 2013.
} 
This is particularly interesting as cultural rights have traditionally been underappreciated. As Shaheed correctly points out, there is support for these rights in the International Bill of Human Rights as well as in the more recent UN Declaration on the Rights of Indigenous Peoples (2007). Also, UNESCO has produced both soft law within several distinct areas of cultural rights and policy - the right to education, linguistic rights, traditional culture and folklore, and cultural diversity - and binding treaties relevant to the area of cultural rights and to the protection of cultural heritage, both material and immaterial.

\section{(b) The Link Between Culture and Science}

The second theme that underlies all Shaheed's reports is the link between culture and science. Both relate to the pursuit of knowledge and understanding as well as to human creativity. Just as the right to participate in cultural life enables people to continuously be creative and contribute to society's cultural meanings and manifestations, so the right to science gives people the freedom to engage in critical thinking and to investigate and contribute new knowledge in the field of science.

In her thematic report on the right to enjoy the benefits of scientific progress and its application (see Chapter 4), Shaheed relates the link between culture and science to the need to protect academic research and academic standards. It is interesting in this context to recall how the word 'scientist' was born. It happened, science philosopher Laura J. Snyder tells us, at the third meeting of the British Association for the Advancement of Science in 1833. The famous poet Samuel Taylor Coleridge was present at this meeting, and he succeeded in alienating everyone by attacking the host, William Whewell, for referring in his opening remarks to the scholars in the audience as 'natural philosophers'. They were no such thing, Coleridge argued; they were practical men who got their hands dirty by experimenting with electricity or digging for fossils. After quieting down the audience who took this as an insult, Whewell actually agreed that Coleridge had a point and coined the phrase 'scientist' to describe the emerging professionalized practice of modern science. ${ }^{22}$ Whewell came to the phrase 'scientist' by analogy with 'artist': much as the artist is typically more interested in doing art than in philosophizing about what it is or ought to be, so the modern scientist conducts experiments (and digs) in accordance with a clear set of rules set by

22 Snyder, 2011, pp. 1-2. 
academic standards on research, including checks and controls, and may not be expected to speculate about the more philosophical aspects of science. ${ }^{23}$

As we shall see, in her 2012 report on the right to enjoy the benefits of scientific progress and its application (discussed in Chapter 4) as well as in her two 2015 reports on IP both of which relate IP policy to the right to science and culture (discussed in Chapters 10 and 11), Shaheed describes access to both science and culture as major, transformative tools for realizing and making dreams come true. Likewise, in an interview that we conducted with her in November 2015 in Copenhagen, Shaheed stressed how learning to appreciate the connection between science and culture has been one of the most useful lessons she has learned as UN Special Rapporteur. ${ }^{24}$ The connection between the two is based, Shaheed also writes in Chapter 1 of this volume, on human creativity being involved in both cultural and scientific activity. This is especially interesting in light of the general assumption that the domains of science and technology are very different from the domains of the arts and humanities - an assumption that is often expressed with reference to the famous 'two cultures' debate between the two Cambridge, UK colleagues, C.P. Snow and F.R. Leavis about higher education and core curricula. ${ }^{25}$

C.P. Snow gave his famous lecture, 'The Two Cultures and the Scientific Revolution,' at the University of Cambridge in 1959. ${ }^{26}$ What has since come to be known as 'the two cultures' debate concerned the gap - and the proper balance - between the technological and natural sciences on the one hand, and the humanities on the other. In his lecture, Snow (a writer of fiction who also had a PhD in chemistry) had argued that the British educational system had over-rewarded the humanities (especially Latin and Greek) at the expense of scientific and engineering education with the result that people in politics, administration, and industry were ill-equipped to manage the modern scientific world.

The reaction of Professor of English and famous literary scholar F.R. Leavis to Snow's lecture was delivered in his 1962 Richmond Lecture, 'Two Cultures? The Significance of C.P. Snow.' Snow mainly dealt in

23 Ibid., 3. - We wish to thank Peter Hjertholm for drawing our attention to this interesting, historical event.

24 'UCPH Talking About - Negotiating Cultural Rights', Helle Porsdam interviewing Farida Shaheed, November 13, 2015 - available at http:// video.ku.dk/secret/12446221/64f4083b0fdbbbde433687327261b013.

25 For a longer and more thorough discussion of this, see Porsdam, 2013.

26 Snow, 1998. 
clichés and preached a way of salvation, Leavis argued, that entailed welfare for all in terms of material, quantitative standards of living and advantages of technology only. What quantitative methods are not very good at handling can in fact well be the things that matter most: the big questions about life and death which may at its best produce great art and literature. Things were changing so rapidly, and critical reflection was needed to help make sense of it all - and to prevent the worst scientific blunders which, in the atomic day and age, could have catastrophic results. Moreover, important ethical issues could well be at stake, Leavis maintained - issues that perhaps scientists themselves would not be aware of. 27

The 'two cultures' debate has since surfaced in different contexts. Thinking about the relationship between science and culture when she was first appointed Special Rapporteur, Shaheed had what she calls in her reflections (Chapter 1) an 'epiphany' - namely:

that at the core of cultural rights is human creativity, regardless of whether this is in terms of science, technology or artistic expression. The right to science is encompassed in the broader right of all human beings to not only create (an essential part of cultural life), but also to enjoy the fruits of the creativity of others while preserving the right of authors, read as including all manner of creators, to the moral and material benefits of that creativity. ${ }^{28}$

It does, in other words, make sense to regard and discuss the three parts of Article 15,1 ICESCR as being not so much at odds with each other, but instead as belonging together.

In her report on the right to enjoy the benefits of scientific progress and its application, at which we shall take a closer look in Chapter 4, rather than simply lining up side by side quantitative knowledge with more qualitative, cultural approaches to knowledge, Shaheed consequently advocates for something closer to a merging of science and culture. Likewise, in her two last reports on intellectual property, the issue of the moral and material benefits of creativity is linked very prominently to the right to science. There really no longer seems to be two, but only one culture or 'cultural capability' left. ${ }^{29}$ The possible implications are interesting - as Lea Shaver, who served as a consultant

\footnotetext{
Leavis, 1962, 25-6.

Shaheed, Ch. 1, this Volume.

$\mathrm{A} / \mathrm{HRC} / 20 / 26$, para 20.
} 
to Shaheed on her report on the right to enjoy the benefits of scientific progress and its application, ${ }^{30}$ puts it:

... there is no clear dividing line between 'culture' and 'science.' Consider, for example, the issue of ensuring widespread access to scientific publications and scholarship. Would this belong in the 'culture' report, because it deals with text and publication? Or is it an issue of science, because the subject matter of the publication pertains to engineering and medicine? If the latter, must we treat scholarship about physics differently from scholarship about poetry? Indeed, scientific inquiry, theory, and literature, as well as technological innovation and products, are themselves properly recognized as cultural manifestations. ${ }^{31}$

\section{THE CHAPTERS}

Reflecting the 'two cultures' debate and Shaheed's argument that there is no clear dividing line between culture and science, the present volume is an interdisciplinary endeavour. When it comes to the setting of cultural (as well as other human) rights - the way in which they are formulated in international treaties and domestic and international law, and applied in practice in national constitutional and legal systems - law is obviously a key discipline. But it is not the only one; a purely legal approach fails to take into account the ethical, historical, political, economic, anthropological - and in the case of Article 15.1(b) ICESCR on the right to benefit from scientific progress and its applications also the natural/technical sciences - dimensions of these rights. These are just as important and it is only by integrating data, tools, perspectives and theories across faculties and disciplines in law, the humanities, and the social and natural/technical sciences that we can begin to get a sense of the full cultural rights picture.

A first, introductory chapter is written by Farida Shaheed. It forms a companion piece to Chapter 2, written by Lotte Hughes, on Shaheed's first report - a report that was especially important as it outlined the mandate of the UN Special Rapporteur in the field of cultural rights and discussed basic definitions and topics of relevance to the field. Several of Shaheed's most important arguments and reflections on her mandate and her time as Special Rapporteur have already been touched upon. We are privileged to be able to print Shaheed's reflections. It is not all that

30 Shaver, 2016, 30: 'producing drafts, participating in all meetings organized to solicit expert feedback on the drafts, and collaborating on their finalization'.

31 Ibid., 31. 
common for a Special Rapporteur to offer such reflections, and Shaheed's will help map for future generations the beginnings of and the early developments within the new and exciting field of cultural rights. Lotte Hughes' comments, in Chapter 2, on Farida Shaheed's first Report are based on her research in Kenya on the interplay between customs and cultural practices of local communities and government policies. Her experiences present a unique opportunity to discuss some of the issues that are distinguished in the first and most general Report. Of particular interest is her analyses of the use of the 'ubiquitous' term community. Hughes warns that this overused and under-defined term should be applied with care, as she finds that this term has served an array of social, political and legal ends, and often seems to result more in the exclusion of non-participants than in a better understanding of the participants in a specific group. Alternatives like collective or social group would better describe a particular group in a particular context. Hughes' account of her research on the contacts between local communities and the Kenyan Government demonstrates clearly how the application of terms like community, or identity in real situations may not reflect what was intended to be achieved by the protection of cultural rights on a more abstract level.

Another issue discussed by Hughes is that of 'self-ascription' - a concept that refers to the identification of groups not only by objective, but also by subjective factors. Hughes points out the delicate line between real and 'invented' traditions. She questions the UN practice that seems to avoid objective criteria to decide which claims should be considered to have a legitimate historical base, and who should be recognized as a representative for these claims.

In Chapter 3, Lucky Belder discusses the second 2011 Report on 'Access to Cultural Heritage'. Affirming the importance of cultural diversity, the report's conclusions and recommendations are all based on the implicit assumption that cultural diversity is conditional to ensuring an enabling environment for the access to cultural heritage, Belder demonstrates. She begins the chapter by marking the occasion that for the first time, a UN document explicitly links a human rights-based approach to the right to express one's identity and the right of access to cultural heritage.

Next, she focuses on which actors could be considered responsible for this right of access to cultural heritage. Recent developments in international human rights law signal an increasing role for non-state actors, and Belder concludes that the implementation of cultural rights has come to include a principle of responsibility that relates not only to states, but also to other public institutions as well as to corporate enterprises and 
civil society. In the final part of her chapter, Belder establishes that the 2015 UNESCO Declaration on the protection and promotion of museums and collections incorporates this principle, by calling upon museums as institutions, but also on museum professionals and civil society at large to observe and implement the principles of instruments for the protection of cultural heritage.

Chapter 4, written by Helle Porsdam and Matthias Mann, concerns Shaheed's 2012 report on the right to enjoy the benefits of scientific progress and its applications. Shaheed starts her third thematic report by stressing the strong link between the right to science and other human rights, especially the right to participate in cultural life. She then outlines the normative content of the right to science, and this normative content and the recommendations made in 'The right to science' report form the point of departure for the four sections of Porsdam's and Mann's chapter.

In the first section, they focus on the link Shaheed makes between the right to science and the right to culture. The second section discusses 'the access perspective': the need to ensure that science and technology will be of benefit to everyone, not least the most vulnerable groups around the world. Then Porsdam and Mann turn, in section 3, to 'the protection perspective': the need to foster an environment that protects the individual researcher and enables him/her to produce and then subsequently disseminate, alone or together with his/her group, scientific knowledge. Finally, section 4 analyzes and comments upon Shaheed's 'areas for further consideration': the right to science and intellectual property; the equitable sharing of benefits and transfer of knowledge; and third-party actors and their obligations (the private-public divide). Porsdam and Mann end by suggesting a fourth area that, in their opinion, merits further consideration - namely, the possible clash between (fundamentalist) religion and science. Along the way, they also offer other suggestions for topics or areas that they think need attention and/or clarification.

Yvonne Donders is the author of Chapter 5. Culture is often seen as an obstacle to the enjoyment of human rights by women. The 2012 report by the Special Rapporteur called 'Enjoyment of cultural rights by women on an equal basis with men' focuses on a more positive role of culture for women. Culture is not only an impediment to, but also an important instrument for the realization of their human rights. The report fits in the more general approach taken by the Special Rapporteur to emphasize the importance of cultural rights for the enjoyment of other human rights, Donders demonstrates. This report is a very comprehensive document on cultural rights and women. Its title suggests that the report is mainly about the equal enjoyment of cultural rights by women and men, but, as Donders points out, the report deals with much more than that. Notably, 
it elaborates on the role of women in the development, preservation and decision-making of issues that relate to culture.

In other words, Donders shows, the report is not only about the (cultural) rights of women, but about cultural rights and gender. Gender roles and especially gender stereotypes play an important role in the (lack of) advancement of women's cultural rights and in the defense of cultural practices harmful to women. The report provides an important contribution to the discussion on these topics by not painting a mere negative picture of the relationship between cultural rights and women, but by emphasizing the importance of cultural rights to empower women and to transform cultures. As such, the report could, Donders concludes, serve as a helpful tool for states and other stakeholders to better understand and implement cultural rights for all, including women and girls.

Both Chapter 6 and Chapter 7 discuss Shaheed's 2013 report on 'The right to freedom of artistic expression and creativity.' Shahira Amin bases her chapter (Chapter 6) on her own country, Egypt. Rights groups have, she states, hailed Egypt's 2014 Constitution as 'one that protects and guarantees freedom of artistic expression,' saying it was more progressive than previous constitutions. Yet, a huge gap still exists between constitutional protection for expression and the reality on the ground faced by Egypt's artists.

The 2011 Revolution had raised hopes for increased freedom of expression - for decades constrained by strict censorship - but, sadly, a culture of repression still prevails. Outlining a number of recent Egyptian cases, Amin shows how art that addresses politics, religion and sex continues to be censored in the name of protecting public order, morality and state interests. The new Constitution, which passed with overwhelming support in early 2014, states that 'public morals, ethics, traditions, customs, values, culture and heritage determine society's evolution and guarantee the rights and liberties of all individuals'. The reality is different, however. The effects of censorship on the arts and the unjustified restrictions on artistic expression are stifling artists in post-revolution Egypt.

Stina Teilmann-Lock approaches Shaheed's report on artistic freedom from a somewhat different angle. Her focus (in Chapter 7) is on intellectual property law and freedom of expression, and she points to a sometimes overlooked motivation identified by Shaheed, namely the 'protection of corporate interests'. There is a desire to silence criticism of corporate activities by artists, and to protect a specific logo or brand from mockery or parodic use. Indeed, in a world where branding has become a major generator of cultural significance there is likely to be a conflict of interest between corporations that aim to control the meanings associated 
with their brands and artists who aim to critique the cultural significance of such brands, Teilmann-Lock demonstrates, following Shaheed. In disputes of this type corporations have been seen to invoke their intellectual property rights as a means to curb artistic expression of which they disapprove on economic grounds.

One such clash between a corporation and an artist is mentioned by Shaheed (in a footnote): that of Nadia Plesner v. Louis Vuitton. This case was the result of a controversy involving the Danish-born visual artist Nadia Plesner and the holders of the right to use the luxury brand 'Louis Vuitton'. As Teilmann-Lock shows, the case is an example of how legislation - whose intended purpose was obviously not to impose censorship - can turn out to be one of the "multi-faceted ways in which the right to the freedom indispensable for artistic expression and creativity may be curtailed'. Intellectual property law is designed to protect the rights of creators and innovators so as to stimulate investments in commerce and arts that will be beneficial to society. However, TeilmannLock concludes, the way in which intellectual property rights are enforced may, in effect, transform them into an instrument of censorship to be invoked by corporations or other private actors.

Shaheed's two consecutive reports 'Writing and teaching of history' (2013) and 'Memorialization processes' (2014) are the topic of Chapter 8, authored by Hanne Hagtvedt Vik. During her travels as the UN Special rapporteur in the field of cultural rights, Shaheed frequently encountered intense disagreements over events in the past and found that across the world people(s) are prevented from accessing historical narratives not only of their own cultural heritage, but also of that of others. Her history and memory reports deal with post-conflict and divided societies and build on the observation that international human rights treaties proclaim the right of all humans to their cultural heritage, and that this includes knowing the past. But to which cultural heritage and history do we have the right, Vik asks? And what would characterize human rights-based approaches to the past? Shaheed offers normative statements and guidance primarily for states, but also for other actors involved in historical research, teaching and memorialization processes.

Shaheed's principal proposition is the advancement of 'multi-voiced narratives' of the past. This and other propositions emanate from a commitment to making sure that history teaching and memorialization do not lead to the (escalation of) conflicts, that victims are recognized, and that the teaching of history and memorialization build on the principles behind the rights to freedom of opinion and expression, as well as the rights to information and academic freedom. Shaheed is concerned that historical narratives may be manipulated for the sake of forging national 
(and other) identity. These concerns and purposes embody inherent tensions, however, some of which are perhaps irreconcilable. Having summarized the two reports and reflected on some of the reports' main propositions and assumptions, Vik ends by suggesting a future path for the present Special Rapporteur with regard to the fields of history and memory.

Chapter 9 concerns Shaheed's 2014 report on 'The impact of commercial advertising and marketing practices on the enjoyment of cultural rights.' Dalindyebo Shabalala's commentary of this report brings up the issue of the focus of the report on the frame of competition law, and the effects of advertising as commercial practice resulting in the imposition and manipulation of choice and options. In response, Shabalala leans towards a 'cultural ecology' approach, presenting a broad interpretation of advertising, not so much referring to the commercial nature of the speaker, but more to advertising as a method of persuasion that may be harmful to the free access to information. Persuasive methods may be applied by commercial enterprises inducing consumers to buy certain products, but, increasingly, similar methods are used by political or religious groups. Shabalala supports the conclusion of the Rapporteur that a mix of regulatory measures and self-regulation is called for, and that an independent regulator should engage in monitoring and standard setting in access to and the use of media rather than in enforcing rules post-violation.

The last two chapters offer commentaries on Shaheed's two 2015 reports on intellectual property as it relates to the right to science and culture. In Chapter 10, Fiona Macmillan looks at the report on copyright policy. In drawing critical attention to a wide range of issues impacting on the operation of copyright law and, especially, the international copyright regime, Shaheed's report has courageously gone where few other institutions of public international governance have dared to go. This territory is not uncharted, however, as Macmillan points out. A considerable number of academic and activist commentators have already set up camp there. The challenge now is to build upon this report by bringing to light further matters of substantial importance in understanding the relationship between copyright and the realization of cultural rights. In this chapter Macmillan offers comments on a range of issues raised or touched on in the copyright report, but which she considers deserve further consideration. There is a yardstick according to which these issues have been selected, and this yardstick is a set of principles and observations that she suggests are fundamental to finding our way to a system that recognizes and promotes creativity and cultural rights. 
Measuring itself according to this yardstick, Macmillan's chapter examines six critical issues raised by the copyright report: private property over cultural output; the problem of corporate ownership of copyright; the uses of human rights discourse; the particular position of Indigenous Peoples; the challenges posed by digital technologies; and the problem of the apparently ever-decreasing (or, maybe, ever-increasing) cultural commons.

The theoretical framework to which Jannice Käll relates her comments in Chapter 11 is that of the so-called 'new materialists' who suggest that we currently live under 'advanced capitalism'. Following 'the new materialists' she argues that the conflicts between patents and human rights make very specific sense in relation to a new materialist understanding of capitalism, and that the conceptual battle between patents and human rights also needs to be fought against the force(s) of advanced capitalism. In order to highlight the severity of the patent regime today as it aligns with capitalism, it is important to pay special attention to issues that rupture the dominating idea of the human as a person who produces and has control over culture and science through property.

Käll addresses the general emphasis in Shaheed's final report on the importance of supporting the creation of free and non-political forms of science. As outlined in the Report, it is today specifically worrisome that patent control is used as a means to govern science even when it is publicly funded. Thus, the politicization of science through marketization and the role of neoliberalism in turning the university into something akin to a company may be understood as a specific threat to the realization of science.

\section{REFERENCES}

A/HRC/14/36 (2010)

A/HRC/20/26 (2012)

An-Na'im, Abdullahi A. (1992), Human Rights in Cross-Cultural Perspectives: A Quest for Consensus (Philadelphia: University of Pennsylvania Press).

Bidault, Mylène (2016), 'Intellectual Property Policies and the Right to Science and Culture: The Work of the Special Rapporteur in Context,' in Christophe Geiger (ed.), Intellectual Property and Access to Science and Culture: Convergence or Conflict? Global Perspectives for the Intellectual Property System, CEIPI-ICTSD, Issue Number 3, 2016, 21-9.

Geiger, Christophe (2016) (ed.), Intellectual Property and Access to Science and Culture: Convergence or Conflict? Global Perspectives for the Intellectual Property System, CEIPI-ICTSD, Issue Number 3. 
Jensen, Steven L.B. (2016) The Making of the International Human Rights, (Cambridge University Press).

Leavis, F.R. (1962), Two Cultures? The Significance of C.P. Snow. The Richmond Lecture (London: Chatto \& Windus).

Lenzerini, Federico (2014), The Culturalization of Human Rights Law (Oxford: Oxford University Press).

Logan, William, 'World Heritage and Human Rights: Preserving our Common Dignity through Rights Based Approaches' (2012) 18(3) International Journal of Heritage Studies 231-44.

Macmillan, Fiona (2017), 'Cultural Heritage and the Unseen Community'. Forthcoming in S. Whatley, C. Waelde, A. Brown and S. Harmon (eds), Dance, Disability and the Law: Invisible Difference (Intellect Books).

Porsdam, Helle (2013), 'Digital Humanities: On Finding the Proper Balance between Qualitative and Quantitative Ways of Doing Research in the Humanities,' Digital Humanities Quarterly 7.2/2013 - available at http://www.digital humanities.org/dhq/vol/7/3/000167/000167.html.

Shaver, Lea (2016), 'Intellectual Property and the Right to Science and Culture: The Reports of the Special Rapporteur in the Field of Cultural Rights,' in Christophe Geiger (ed.), Intellectual Property and Access to Science and Culture: Convergence or Conflict? Global Perspectives for the Intellectual Property System, CEIPI-ICTSD, Issue Number 3, 2016, 30-41.

Snow, C.P. (1998), 'The Two Cultures. The Rede Lecture, 1959', in C.P. Snow The Two Cultures (Cambridge: Cambridge University Press).

Snyder, Laura J. (2011), The Philosophical Breakfast Club: Four Remarkable Friends Who Transformed Science and Changed the World (New York: Broadway Paperbacks). 
Lucky Belder and Helle Porsdam - 9781786435422 Downloaded from PubFactory at 04/26/2023 $04: 46: 40$ AM via free access 